\title{
Batch and fixed-bed adsorption of tartrazine azo-dye onto activated carbon prepared from apricot stones
}

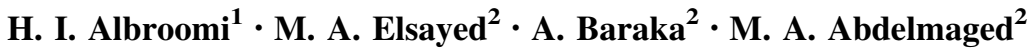

Received: 8 October 2015/Accepted: 27 January 2016/Published online: 11 February 2016

(c) The Author(s) 2016. This article is published with open access at Springerlink.com

\begin{abstract}
This work describes the potential of utilizing prepared activated carbon from apricot stones as an efficient adsorbent material for tartrazine (TZ) azo-dye removal in a batch and dynamic adsorption system. The results revealed that activated carbons with well-developed surface area $\left(774 \mathrm{~m}^{2} / \mathrm{g}\right)$ and pore volume $\left(1.26 \mathrm{~cm}^{3} / \mathrm{g}\right)$ can be manufactured from apricot stones by $\mathrm{H}_{3} \mathrm{PO}_{4}$ activation. In batch experiments, effects of the parameters such as initial dye concentration and temperature on the removal of the dye were studied. Equilibrium was achieved in $120 \mathrm{~min}$. Adsorption capacity was found to be dependent on the initial concentration of dye solution, and maximum adsorption was found to be $76 \mathrm{mg} / \mathrm{g}$ at $100 \mathrm{mg} / \mathrm{L}$ of TZ. The adsorption capacity at equilibrium $\left(q_{\mathrm{e}}\right)$ increased from 22.6 to $76 \mathrm{mg} / \mathrm{g}$ with an increase in the initial dye concentrations from 25 to $100 \mathrm{mg} / \mathrm{L}$. The thermodynamic parameters such as change in free energy $\left(\Delta G^{0}\right)$, enthalpy $\left(\Delta H^{0}\right)$ and entropy $\left(\Delta S^{0}\right)$ were determined and the positive value of $(\Delta H) 78.1\left(\mathrm{~K} \mathrm{~J} \mathrm{~mol}^{-1}\right)$ revealed that adsorption efficiency increased with an increase in the process temperature. In fixed-bed column experiments, the effect of selected operating parameters such as bed depth, flow rate and initial dye concentration on the adsorption capacity was evaluated. Increase in bed height of adsorption columns leads to an extension of breakthrough point as well as the exhaustion time of adsorbent. However, the maximum adsorption capacities decrease with increases of flow rate. The breakthrough data fitted well to bed depth service time
\end{abstract}

\footnotetext{
M. A. Elsayed

aboelfotoh@gmail.com

Oman Armed Forces, Masqat, Oman

2 Chemical Engineering Department, Military Technical College, Egyptian Armed Forces, Cairo, Egypt
}

and Thomas models with high coefficient of determination, $R^{2} \geq 94$.

Keywords Adsorption of tartrazine azo-dye $\cdot$ Apricot stones · Fixed-bed column · Breakthrough curve

\section{Introduction}

Azo-dyes as an aromatic molecular structure compound are generally resistant to light, biodegradation, temperature, ozonation and oxidation. This significant properties makes the dyes to be accumulated in the living organisms and therefore leading to severe diseases and function disorders (Gautam et al. 2015b). The issue of the presence of color in effluent has received considerable critical attention for dyestuff manufacturers and textile companies (Annadurai et al. 2002). This is because increasingly stringent water quality standards which have been used to controlling and reducing discharge of hazardous substances in effluent (Yavuz and Aydin 2006; Santhy and Selvapathy 2006). Nowadays, there is a primary concern of decolorization and treatment of wastewater because many industries depend on dyes to color their products such as textiles, leather and food processing industries (Robinson et al. 2001). There are various physical and chemical treatment processes for organic dyes removals from wastewater have been applied. The most important treatment processes are coagulation and flocculation, photo-degradation, biosorption, oxidizing agents, membrane and ultra-filtration. The advantages, disadvantages and limitations of each technique have been extensively studied by many researchers (Namasivayam and Suba 2001; Robinson et al. 2001; Gurses et al. 2004; Klán and Vavrik 2006). Due to many draw-backs such as, complexity of the process, low removal efficiencies and 
relatively high operating costs using the above-mentioned techniques, dyestuff manufacturers and paper industries seldom apply these methods to treat their wastewater effluents (Robinson et al. 2002; Kadirvelu et al. 2003). However, regarding to initial operating costs, ease of operation, simplicity of equipments design, adsorption onto activated carbon process has been found to be an efficient and economic process to remove dyes and other pollutant from wastewater (Annadurai and Lee 2002; Grégorio Crini 2010; Algidsawi 2011).

Although batch adsorption studies provide useful data and parameters on the application of specific adsorbents for the removal of dyes or specific pollutant, continuously fixed bed or column experiments are also necessary to provide practical operational information with respect to the adsorption of constituents with the use of a particular adsorbent (Ahmad and Hameed 2010; Dutta and Basu 2014). Fixed-bed columns can be operated singly, in series or in parallel. Small-scale column tests can be employed to simulate the potential performance of the adsorbent and the results obtained extrapolated in the design of full-scale reactors (Walker and Weatherley 1997; Futalan et al. 2011; Mulgundmath et al. 2012).

Tartrazine is a synthetic lemon yellow azo-dye authorized in many countries in food processing manufacture with maximum permitted use levels of $50-500 \mathrm{mg} / \mathrm{kg}$ food for various food processing. It is also known as $\mathrm{E}$ number E102, C.I. 19140, FD\&C Yellow 5, Acid Yellow 23, and Food Yellow 4. Reduction of Tartrazine may produce sulphonated aromatic amines compounds, which have low toxicity potential (Aguilar et al. 2009). Tartrazine is considered to be toxic to humans as it acts as hyperactivity and causes asthma, migraines, eczema, thyroid cancer and other behavioral problems (Gautam et al. 2015a).
On the basis of the previous discussions, the focus of this research was to evaluate the adsorption potential of the Apricot stone-based activated carbon in removing Tartrazine azo-dye from aqueous solutions through batch and fixed-bed experiments. Batch adsorption experiments were conducted using synthetic aqueous solutions of tartrazine and the effects of initial dye concentration and temperature were investigated. Thermodynamics of the adsorption process has also been studied and the changes in Gibbs free energy, enthalpy and the entropy have been determined. In column experiments, effects of parameters such as flow rate, initial concentration of TZ, and fixed-bed height on TZ adsorption using; Thomas, bed depth service time (BDST) and AdamsBohart kinetic models were considered.

\section{Experimental}

\section{Materials and apparatus}

Tartrazine dye supplied by Morgan Chemical Company was used without further purification to prepare all synthetic wastewater solutions. It was kept in a tightly sealed bottle to prevent any contaminations and assure the material quality. Other reagents include phosphoric acid $\left(\mathrm{H}_{3} \mathrm{PO}_{4}\right)$, dilute $\mathrm{HCl}$ and $\mathrm{NaOH}$ solutions. All reagents were of analytical grade. Deionized water was used throughout the experiments. The dyes concentrations were determined using Agilant UV-Vis Cary 60 PC scan double beam recording spectrophotometer using (1) $\mathrm{cm}$ glass cells. The measurement of Tartrazine concentration was conducted at $\lambda_{\max }=425 \mathrm{~nm}$. A digital $\mathrm{pH}$ meter, type 720 WTW 82362 was used to adjust the pH. Schematic structure of Tartrazine and its properties are shown in Table 1.

Table 1 Schematic structure of Tartrazine and its properties

Properties
Chemical structure
Trisodium $(4 E)-5$-oxo-1-(4-sulfonatophenyl)-4-[(4-sulfonatophenyl)hydrazono]-3-pyrazolecarboxylate
Chemical name
Molecular formula
Molecular weight $(\mathrm{g} / \mathrm{mol})$




\section{Adsorbent preparation}

In this study, activated carbon was prepared from apricot stones by chemical activation technique using phosphoric acid $\left(\mathrm{H}_{3} \mathrm{PO}_{4}\right)$ as activating agent. Chemical activation is known by its advantage compared to physical activation in crosslinking and protective of carbon skeleton and its participation in the creation and expansion of the pores (Deng et al. 2009). In addition, chemical activation using phosphoric acid is known to prevent excessive sample burn-off, resulting in high yield and well-developed internal porosity. Firstly, the apricot stones were dried at room temperature then crushed with a jaw crusher. The resulting particles were sieved and the particles having sizes between 1-2 $\mathrm{mm}$ were used in the rest of the experimental work. Then samples were treated with the $50 \%$ (vol) $\mathrm{H}_{3} \mathrm{PO}_{4}$ solution at $25{ }^{\circ} \mathrm{C}$ at ratio of $2.5: 1$ (weight) for $24 \mathrm{~h}$.

After impregnation, solution was filtered to take the residual acid. Subsequently impregnated samples were air dried at room temperature for 3 days. Impregnated apricot stones samples containing $\% 18 \mathrm{H}_{3} \mathrm{PO}_{4}$ were obtained after drying. To produce activated carbon, acid impregnated samples were heated; at a heating rate of $20{ }^{\circ} \mathrm{C} / \mathrm{min}$ to the final carbonization temperatures, $700{ }^{\circ} \mathrm{C}$, for $180 \mathrm{~min}$. Before the characterization, products were crushed to obtain small particles (30-70 mesh or $0.595-0.212 \mathrm{~mm}$ ) and rinsed with boiling distilled water to decrease the $\mathrm{pH}$ value of the activated carbon.

\section{Physicochemical characterization of the adsorbent}

BET surface area and micropore volume of each activated carbon were determined from the $\mathrm{N}_{2}$ adsorption experiments. Approximately $0.12 \mathrm{~g}$ samples were heated to $250{ }^{\circ} \mathrm{C}$ to remove all the adsorbed species. Nitrogen adsorption and desorption isotherms were then taken using Quantrachrome Autosorb I-CLP Surface Area Analyzer (Micromeritics Instrument Corp.). According to the resulting isotherm, the BET surface area $\left(S_{\mathrm{BET}}\right)$, micropore volume $\left(V_{\text {mic }}\right)$, micropore surface area $\left(S_{\text {mic }}\right)$, mesopore volume $\left(V_{\mathrm{BJH}}\right)$, mesopore surface area $\left(S_{\mathrm{BJH}}\right)$, and pore size of the samples were analyzed by BET (Brunauere Emmette Teller) theory, t-plot theory and BJH (Barrette Johnere Halendar) theory, respectively.
For the chemical characterization, the analyses were limited to determination of $\mathrm{C}, \mathrm{H}, \mathrm{N}, \mathrm{O}$ elements, ash analysis and FTIR; to provide information with respect to elemental composition and functional groups, respectively. The proximate analysis of the prepared activated carbon was performed according to ASTM standards (Aygun et al. 2003). A carbon/hydrogen/oxygen/nitrogen/sulfur (C/H/O/ $\mathrm{N} / \mathrm{S}$ ) content of activated carbon used in this experimental work was analyzed by elemental analyzer (model CHNORAPID, Heraeus Co., Germany). Table 2 shows the proximate and elemental analyses of the prepared activated carbon from apricot stones.

Perkin Elmer Spectrum Infrared Spectrometer with resolution of $4 \mathrm{~cm}^{-1}$ in the range of $4000-500 \mathrm{~cm}^{-1}$ was used for the FTIR analysis of prepared active carbon. The adsorbent and potassium bromide $(\mathrm{KBr})$ were dried in an oven and then ground together in a ratio of 20:1 (KBr:AC) for FTIR measurement using disk sample method (Gupta et al. 2011).

\section{Batch equilibrium studies}

Adsorption tests were performed in a set of Erlenmeyer flasks $(250 \mathrm{~mL})$ where $100 \mathrm{~mL}$ of TZ solutions with initial concentrations of $25-100 \mathrm{mg} / \mathrm{L}$ were placed in these flasks. Equal mass of $0.1 \mathrm{~g}$ of the prepared activated carbon with the particle size of $0.595-0.212 \mathrm{~mm}$ was added to each flask and kept in an isothermal shaker of $100 \mathrm{rpm}$ at $25^{\circ} \mathrm{C}$ to reach equilibrium. The $\mathrm{pH}$ of the solutions was natural (pH 6.5). Aqueous samples were taken from the solution and the concentrations were analyzed. All samples were filtered prior to the analysis to minimize the interference of the carbon fines with the analysis. The concentrations of $\mathrm{TZ}$ in the supernatant solution before and after adsorption were determined using Agilent UV-Vis Cary 60 PC scan double beam recording spectrophotometer using (1) $\mathrm{cm}$ glass cells. Each experiment was duplicated under identical conditions. The amount of adsorption at equilibrium, $q_{\mathrm{e}}$ $(\mathrm{mg} / \mathrm{g})$, was calculated by:

$q_{\mathrm{e}}=\frac{V}{W}\left(C_{0}-C_{\mathrm{e}}\right)$

where $C_{0}$ and $C_{\mathrm{e}}(\mathrm{mg} / \mathrm{L})$ are the liquid phase concentrations of dye at the initial and equilibrium conditions, respectively. $V$ is the volume of the solution (l) and $W$ is the mass of dry adsorbent used $(\mathrm{g})$.

Table 2 Proximate and elemental analyses of prepared active carbon

\begin{tabular}{|c|c|c|c|c|c|c|c|c|}
\hline \multirow[t]{2}{*}{ Sample } & \multicolumn{3}{|c|}{ Proximate analysis (wt\%) } & \multicolumn{5}{|c|}{ Elemental analysis (wt\%) } \\
\hline & Moisture & Ash & Volatile matter & $\mathrm{C}$ & $\mathrm{H}$ & $\mathrm{N}$ & S & O by diff. \\
\hline $\mathrm{AC}$ & 5.1 & 3.36 & 82.8 & 83.12 & 3.87 & 0.91 & 0.56 & 11.54 \\
\hline
\end{tabular}




\section{Fixed-bed adsorption experiment}

The experiment was conducted in a $2 \mathrm{~cm}$ diameter and $15 \mathrm{~cm}$ length encased Pyrex glass tube having an embedded stainless steel mesh for supporting layer of adsorbent. A schematic of the experimental setup used for column study is shown in Fig. 1. The experiments were conducted by varying the weight of activated carbon and different initial solutions concentration of TZ. The height of the activated carbon bed was measured before the tests to monitor the variation cause by bed height. The Activated carbon 5.6, 7 and $8.4 \mathrm{~g}$ adsorbent corresponding to 8, 10 and $12 \mathrm{~cm}$ bed heights, respectively, were measured into the column. Fluidization and bypass flow of the system were retarded by good packing of the adsorbent. Influent flow rate of 2.7, 4.2 and $5.7 \mathrm{~mL} / \mathrm{min}$ in an upward direction with the aid of peristaltic pump (Master-flex, Cole-Parmer Instrument Co.) were used for 10,15 , and $20 \mathrm{mg} / \mathrm{L}$ initial concentrations of TZ. The effluent TZ concentration was measured at intervals at $\lambda_{\max }=425 \mathrm{~nm}$ UV-Vis spectrophotometer. Experiments were continued until the column reached equilibrium concentration. All experiments were carried out under room temperature $\left(25 \pm 2{ }^{\circ} \mathrm{C}\right)$.

\section{Fixed-bed column data analysis}

Several bed parameters are important for the characterization of any adsorption process. They were determined for each column from the breakthrough curves using previously published calculation methods (Crhribi and Chlendi 2011; Casas et al. 2012; Chen et al. 2012).

The adsorption breakthrough profiles were obtained from $C_{\mathrm{t}}(\mathrm{mg} / \mathrm{L})$ or $C_{\mathrm{t}} / C_{\mathrm{o}}$ vs. $V_{\mathrm{t}}(\mathrm{mL})$ or $t$ plots; where $C_{\mathrm{t}}$ is effluent concentration, $C_{\mathrm{o}}$ influent concentration, $V_{\mathrm{t}}$ volume of effluent treated and $t$ is the service time. The treated effluent volume $V_{\mathrm{t}}$ is determined.as:

$V_{\mathrm{t}}=Q t_{\mathrm{e}}$

where $Q(\mathrm{~mL} / \mathrm{min})$ and $\mathrm{t}_{\mathrm{e}}$ are the influent flow rate and time of exhaustion. Fixed-bed capacity $q_{\text {total }}(\mathrm{mg})$ at set influent

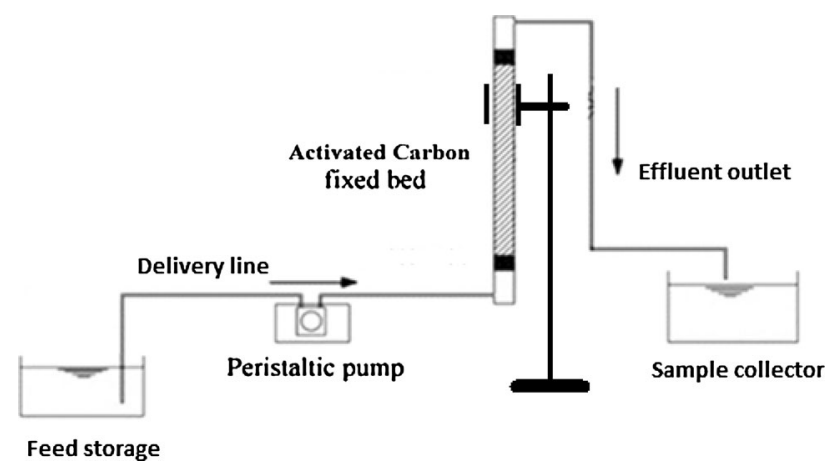

Fig. 1 Experimental setup for the fixed-bed adsorption process conditions (concentration and flow rate) is determined by computation of area under the plot from the integral of adsorbed concentrations expressed as; $C_{\text {ad }}\left(C_{\text {ad }}=C_{\mathrm{o}}-C_{\mathrm{t}}\right) \mathrm{mg} / \mathrm{L}$ for a given time $t$ :

$q_{\text {total }}=\frac{Q A}{1000}=\frac{Q}{1000} \int_{t=0}^{t=t_{\text {total }}} C_{\text {ad }} \mathrm{d} t$

where $t_{\text {total }}$, is the total flow time, $Q$ and $A$ are the volumetric flow rate $(\mathrm{mL} / \mathrm{min})$ and the area under the breakthrough curve, respectively. The equilibrium uptake $\left(q_{\text {eq(exp) }}\right) \quad(\mathrm{mg} / \mathrm{g}) \quad$ can be evaluated using Eq. (4) (Karunarathne and Amarasinghe 2013);

$q_{\text {eq(exp) }}=\frac{q_{\text {total }}}{m}$

where $m(\mathrm{~g})$ is the mass of adsorbent in the column.

\section{Result and discussion}

\section{Adsorbent characterization}

The nitrogen adsorption-desorption isotherms of activated carbon prepared from Apricot stone is depicted in Fig. 2, where the amount of $\mathrm{N}_{2}$ adsorbed at $77 \mathrm{~K}$ is plotted against the relative pressure.

Figure 2 showed that the adsorption-desorption isotherm resemble a combination of types I and IV isotherms (in accordance with the International Union of Pure and Applied Chemistry (IUPAC) classification), which is corresponding to micro-mesoporous solid. The type IV isotherm usually originates from mesoporous solids. It describes a multilayer adsorption process where complete filling of the smallest capillaries has occurred. Whilst type I isotherm is typical of microporous solids where only monolayer adsorption occurs. In these micropores, filling

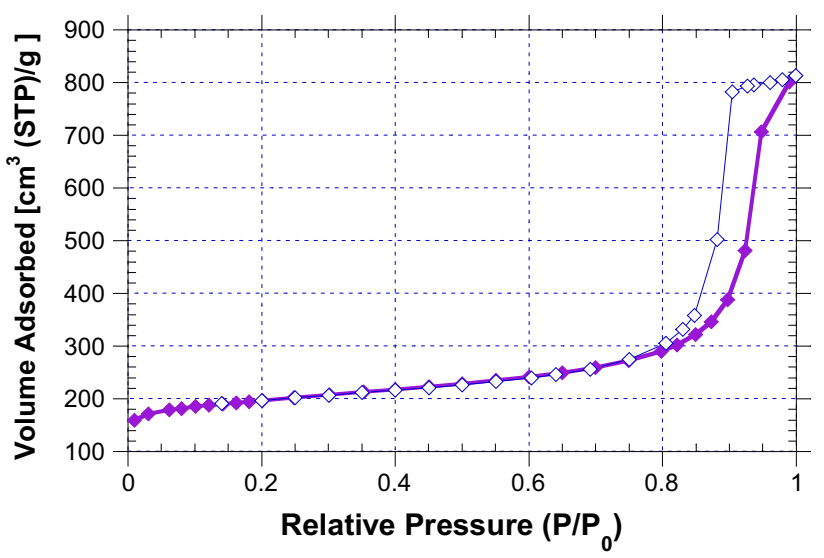

Fig. 2 Adsorption profiles of $\mathrm{N}_{2}$ at $77 \mathrm{~K}$ on the activated carbon prepared from apricot stone. Open keys indicate adsorption whilst closed keys indicate desorption 
occurs significantly at relatively low partial pressure $<0.1$ $p / p_{\mathrm{o}}$, the adsorption process being complete at $p / p_{\mathrm{o}} \approx 0.5$. The main feature of such isotherm is the long plateau which is indicative of a relatively small amount of multilayer adsorption on the open surface. On the other hands, the nitrogen uptake occurs mostly at $\left(p / p_{\mathrm{o}}>0.9\right)$. This indicates that the meso- or macropore structure in the sample significantly developed. The isotherm is characterized by hysteresis loop, which appear in the multilayer rang of physical sorption isotherm. This kind of loop is generally associated with capillary condensation. It is well known that most mesoporous adsorbents give distinctive and reproducible hysteresis loops.

In Table 3 are given some textural parameters obtained from nitrogen adsorption isotherms at $77 \mathrm{~K}$ of the carbons samples prepared by $\mathrm{H}_{3} \mathrm{PO}_{4}$ chemical activation. The results revealed that activated carbons with well-developed porosity and high surface area can be manufactured from apricot stones. These superior properties could provide high concentration of active sites for adsorption of TZ dye to occur.
Knowledge on surface chemistry characteristics of the produced activated chars would give insight to its adsorption capability and behavior (Elsayed and Zalat 2015). FTIR analysis was conducted for qualitative characterization of surface functional groups of porous carbons activated by $\mathrm{H}_{3} \mathrm{PO}_{4}$. The IR spectrum of $\mathrm{AC}$ prepared by $\mathrm{H}_{3} \mathrm{PO}_{4}$ activation is shown in Fig. 3. The FTIR spectra show a number of significant peaks, indicating the complex structure of the chemical activated carbon sample. According to the spectrum, the appearance of bands at $3448.5-3421.5 \mathrm{~cm}^{-1}$ refers to $(\mathrm{O}-\mathrm{H})$ stretching vibrations in the hydroxyl, carboxylic or phenolic groups. The band appears at $2854.5 \mathrm{~cm}^{-1}$ can be assigned to $\mathrm{C}-\mathrm{H}$ group stretching. The band appears at $1635.5 \mathrm{~cm}^{-1}$ can be assigned explained to the olefinic $\mathrm{C}=\mathrm{C}$ stretching. In fact, the $\mathrm{C}=\mathrm{C}$ stretching absorption frequently occurs at approximately nearby $1600 \mathrm{~cm}^{-1}$ for carbonaceous materials (Aygun et al. 2003), The band shift from $1600 \mathrm{~cm}^{-1}$ may be due to conjugation with another $\mathrm{C}=\mathrm{C}$ bond, or a $\mathrm{C}=\mathrm{O}$ bond. The band located at $1384.8 \mathrm{~cm}^{-1}$ could be attributed to $\mathrm{C}-\mathrm{H}$ deformation vibration in alkenes that frequently occurs at approximately at $1381 \mathrm{~cm}^{-1}$. The

Table 3 The characteristic pore properties of resulting activated carbon

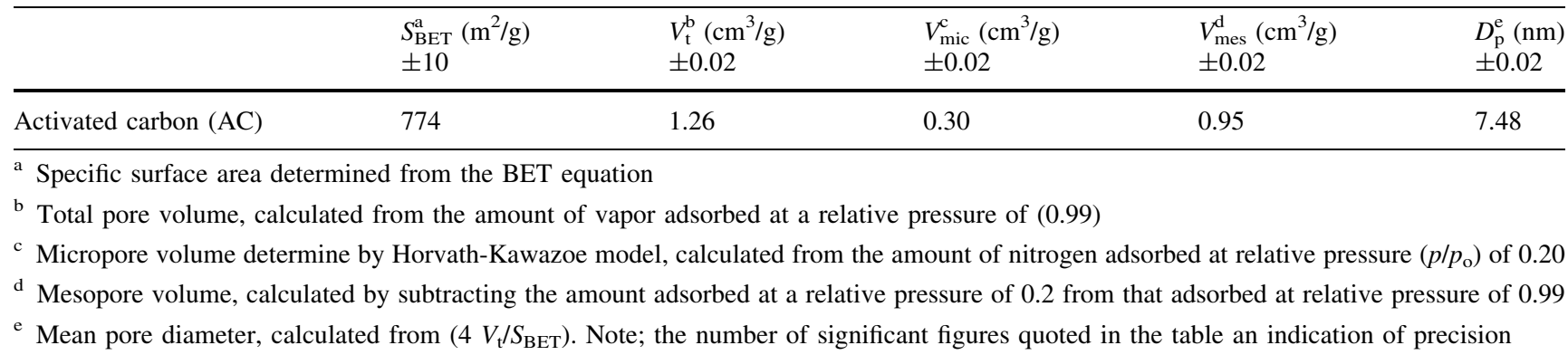

Fig. 3 IR spectrum of prepared activated carbon sample

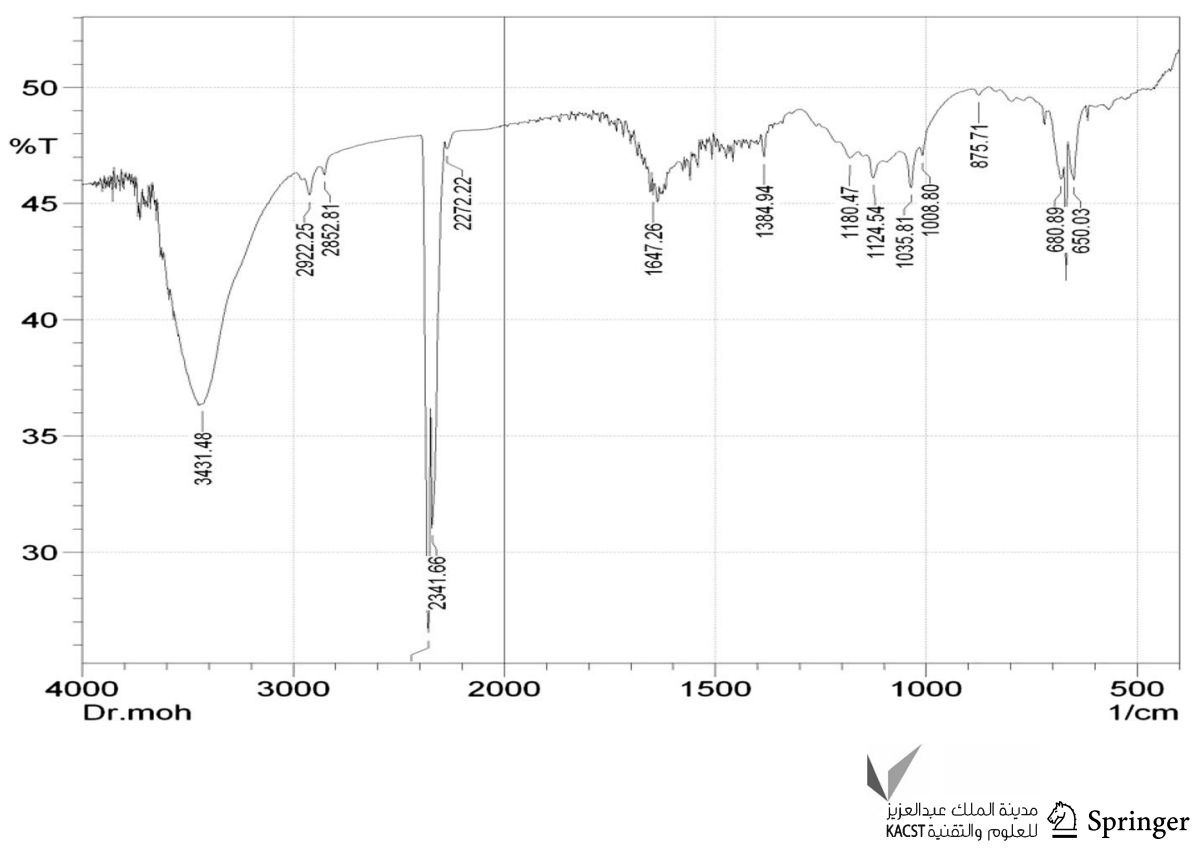


appearance of bands between 1033.8 and $1037.6 \mathrm{~cm}^{-1}$ could be assigned to $\mathrm{C}-\mathrm{O}$ stretching vibrations in phenolic and carboxylic groups. The bands at $680-700 \mathrm{~cm}^{-1}$ may refer to $\mathrm{C}-\mathrm{H}$ vibration. The data mentioned above show the presence of phenolic, carboxylic and hydroxylic groups, which may be responsible for the potential adsorption of TZ dye onto the prepared AC sample (Baraka 2012).

\section{Effect of contact time and initial dye concentration on adsorption equilibrium}

Figure 4 shows the adsorption capacity vs. the adsorption time at various initial $\mathrm{TZ}$ concentrations at $25{ }^{\circ} \mathrm{C}$. It indicated that the contact time needed for TZ solutions with initial concentrations of $25-100 \mathrm{mg} / \mathrm{L}$ to reach equilibrium was $120 \mathrm{~min}$. As can be seen from Fig. 3, the amount of $\mathrm{TZ}$ adsorbed onto the activated carbon increased with time and, at some point in time, it reached a constant value beyond which no more TZ dye was further removed from the solution. At this point, the amount of the TZ dye desorbing from the activated carbon was in a state of equilibrium with the amount of the $\mathrm{TZ}$ dye being adsorbed onto the activated carbon. The amount of dye adsorbed at the equilibrium time reflects the maximum adsorption capacity of the adsorbent under those operating conditions. In this study, the adsorption capacity at equilibrium $\left(q_{\mathrm{e}}\right)$ increased from 22.6 to $76 \mathrm{mg} / \mathrm{g}$ with an increase in the initial dye concentrations from 25 to $100 \mathrm{mg} / \mathrm{L}$. The effect of the initial dye concentration depends on the immediate relation between the dye concentration and the available binding sites on an adsorbent surface (Gautam et al. 2014b).

Generally, the adsorption capacity of activated carbon samples and the percentage of dye removal decrease with an increase in initial dye concentration, which may be due to the saturation of adsorption sites on the adsorbent surface. At low initial dye concentration, there will be unoccupied active sites on the activated carbon surface, and when the initial dye concentration increases, the active sites required for adsorption of the dye molecules will occupy and disappear (Gautam et al. 2013). However, the increase in the initial dye concentration leading to the high driving force for mass causes an increase in the loading capacity of the adsorbent. In other words, the number of dye molecules in the solution will be higher than active sites available on the adsorbent surface for higher initial dye concentrations. In contrast, at the case of lower initial dye concentrations, the ratio of initial number of dye molecules in the solution to the available adsorption active sites on the surface of the adsorbent is low and subsequently the fractional adsorption becomes independent of initial concentration (Gautam et al. 2014a).

\section{Effect of temperature on adsorption equilibrium and thermodynamic parameters}

Figure 5 shows the adsorption equilibrium vs. temperature at initial TZ concentrations $100 \mathrm{ppm}$. It is shown that the adsorption capacity increases with temperature, indicating an endothermic process. It had been investigated from the experiment that with the rise of temperature from 288 to $303 \mathrm{~K}$ the amount of dye uptake increases from 57 to $80 \mathrm{mg} / \mathrm{g}$. As the rate of diffusion of the dye molecules is a temperature controlled process, variation in temperature alters the equilibrium capacity of the adsorbent for a particular adsorbate. In the present study, an increases of the adsorption temperature leads to fast diffusion of dye molecules across the external boundary layer and internal pore structure of the adsorbent particles. This may be due to less resistance offered by viscous forces in the solutio. In addition, in some cases the solubility of the dye molecules is affected with the increase of the temperature which finally has a significant impact on the removal efficiency.

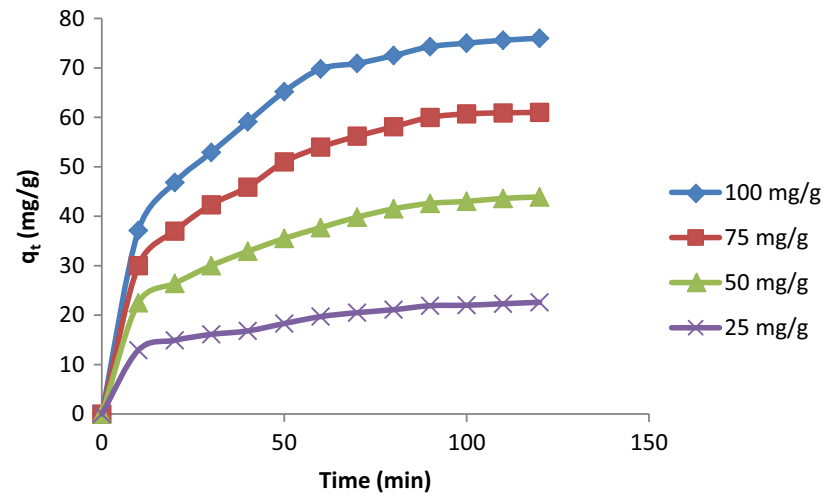

Fig. 4 Adsorption capacity vs. adsorption time at various initial TZ concentrations at $25{ }^{\circ} \mathrm{C}$

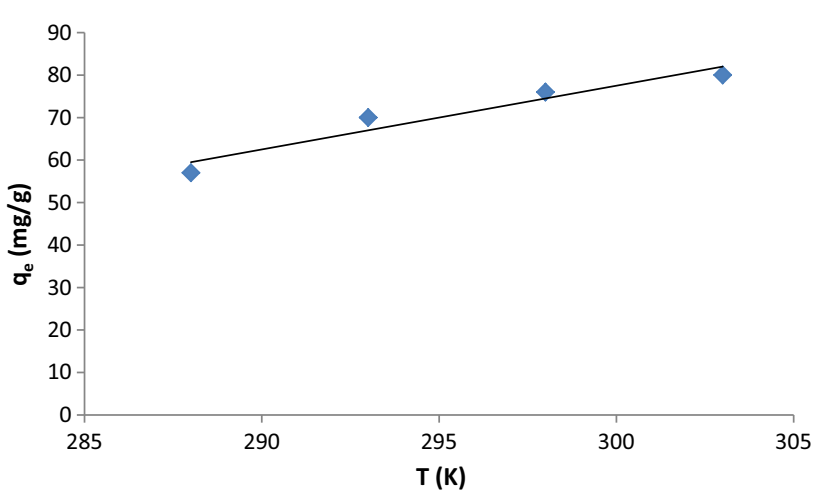

Fig. 5 Effect of temperature on adsorption equilibrium at initial TZ concentrations (100 ppm) 
The thermodynamics of the adsorption process were studied at three different temperatures in a thermostated incubator. Thermodynamic parameters such as the Gibbs free energy change $(\Delta G)$, enthalpy changes $(\Delta H)$ and entropy change $(\Delta S)$ can be used for the characterization of temperature effect on the adsorption process. These parameters were calculated using the following equations:

$\Delta G=-R T \operatorname{Ln} K_{\mathrm{L}}$ (Gibbs equation)

$L n K_{\mathrm{L}}=-\frac{\Delta H}{R T}+\frac{\Delta S}{R}$ (Vant' Hoff equation)

where $K_{\mathrm{L}}=\frac{q_{\mathrm{e}}}{C_{\mathrm{e}}}, R$ is the molar gas constant $(8.314 \mathrm{~J} / \mathrm{mol} \mathrm{K})$ and $T$ is the absolute temperature. $K_{\mathrm{L}}$ is the equilibrium constant obtained for each temperature from the Langmuir model. $\Delta H$ and $\Delta S$ were obtained from the slopes and intercepts of the linear plots of In $K_{\mathrm{L}}$ against $1 / T$ (Figure not shown). The values of the thermodynamic parameters are given in Table 4.

sitive value of $(\Delta H) 78.1\left(\mathrm{~K} \mathrm{~J} \mathrm{~mol}^{-1}\right)$ revealed that adsorption efficiency increased with an increase in the adsorption temperature; this implies that each TZ molecule had to displace more than one water molecule from the adsorbent surface before it is adsorbed. Generally, most of the adsorption studies substantiate the assumption that the adsorption of dye on the active carbon surface is endothermic. Significantly, these high values of $(\Delta H)$ indicate a strong chemical interaction between the active carbon and TZ dye. The negative value of $\Delta G$ reflects the feasibility and spontaneity of the adsorption process. In addition, the value of $\Delta S\left(285 \mathrm{~J} \mathrm{~mol}^{-1} \mathrm{k}^{-1}\right)$ had been expected to be so large which indicated an increase of entropy as a result of adsorption process (Gautam et al. 2013). This can be explained as that, before adsorption occurs, the dyes ions near the active carbon boundary were in ordered form than in the subsequent adsorbed state and the ratio of free dye ions to the captured dye ions with the active carbon will be higher than in the adsorbed state. As a result of adsorption, there will be an increased randomness at solid-liquid interface and the distribution of translational and rotational energy will increase, producing a positive entropy value. In the present study, at high operating temperature, adsorption is likely to occur spontaneously because $\Delta H>0$ and $\Delta S>0$.

Table 4 Values of thermodynamic parameters for the removal of Tartrazine onto AC

\begin{tabular}{llll}
\hline Temperature $(\mathrm{K})$ & $\Delta G\left(\mathrm{~K} \mathrm{~J} \mathrm{~mol}^{-1}\right)$ & $\Delta H\left(\mathrm{~K} \mathrm{~J} \mathrm{~mol}^{-1}\right)$ & $\Delta S\left(\mathrm{~mol}^{-1} \mathrm{k}^{-1}\right)$ \\
\hline 288 & -4.49 & 78.4 & 285 \\
298 & -6.16 & & \\
303 & -9.8 & & \\
\hline
\end{tabular}

\section{Fixed-bed adsorption column study}

\section{Effect of bed height on breakthrough curve}

An effect of bed height on the adsorption of TZ by activated carbon samples is shown in Fig. 6. In this experiment the bed heights were 8,10 and $12 \mathrm{~cm}$ with fixed flow rate of $2.7 \mathrm{~mL} / \mathrm{min}, 15 \mathrm{mg} / \mathrm{L} \mathrm{TZ}$ concentration and $\mathrm{pH}=6.8$.

Increase in bed height of adsorption columns leads to longer breakthrough point as well as the exhaustion time of adsorbent. This is due to increase in the amount of adsorbent in the column which leads to increase in surface area (Khoo et al. 2012). The shape and gradient of the breakthrough curves were slightly different for different bed height.

It was also observed that, the sorption capacity and breakthrough time increased with an increase in the bed height as shown in Table 5. This increase can be attributed to sufficient residence time of $\mathrm{TZ}$ dye in the column adsorption region which provided sufficient time for diffusion or interaction of the dye molecules with the adsorbent. An increase in adsorption capacity of TZ from 1.61 to $2.41 \mathrm{mg} / \mathrm{g}$ was recorded.

The BDST model proposed by Bohart and Adams offer the simplest approach and most rapid prediction of column adsorption performance (Vaňková et al. 2010). The model gives a linear relationship between the time required to

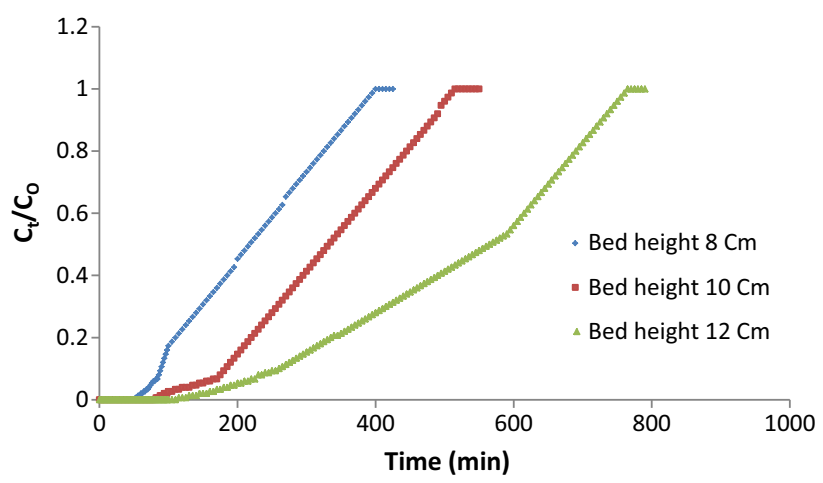

Fig. 6 Effect of bed height on adsorption of TZ by activated carbon (flow rate of $2.7 \mathrm{~mL} / \mathrm{min}$, Initial $\mathrm{TZ}$ concentration of $15 \mathrm{mg} / \mathrm{L}$, and temperature of $25{ }^{\circ} \mathrm{C}$ )

Table 5 Experimental constants of BDST model for TZ adsorption onto activated carbon ( $\mathrm{TZ}$ concentration $=15 \mathrm{ppm}, \mathrm{pH}=6.8$ and flow rate $=2.7 \mathrm{~mL} / \mathrm{min}$ )

\begin{tabular}{|c|c|c|c|c|}
\hline Bed depth & $q_{\mathrm{e}}(\mathrm{mg} / \mathrm{g})$ & $t_{\mathrm{b}}(\min )$ & $t_{\mathrm{e}}(\min )$ & $R^{2}$ \\
\hline $8 \mathrm{~cm}$ & 1.61 & 52 & 425 & 0.99 \\
\hline $10 \mathrm{~cm}$ & 1.78 & 82 & 550 & \\
\hline $12 \mathrm{~cm}$ & 2.41 & 115 & 790 & \\
\hline
\end{tabular}


reach the desired breakthrough concentration and the bed height. The equation can be expressed as follows:

$t=\frac{N_{\mathrm{o}} Z}{C_{\mathrm{o}} Q}-\frac{1}{K_{\mathrm{a}} C_{\mathrm{o}}} \ln \left(\frac{C_{\mathrm{o}}}{C_{\mathrm{t}}}-1\right)$

where $C_{\mathrm{t}}$ is the breakthrough dye concentration $(\mathrm{mg} / \mathrm{L}), C_{O}$ is influent or initial solute concentration $(\mathrm{mg} / \mathrm{L}), N_{0}$ the sorption capacity of bed $(\mathrm{mg} / \mathrm{L}), Q$ the linear velocity $(\mathrm{mL} /$ $\min ), Z$ is the depth of adsorbent bed and $K_{\mathrm{a}}$ is the rate constant (L/mg min).

The plot of service time against bed height at a flow rate of $2.7 \mathrm{~mL} / \mathrm{min}$ was linear indicating the validity of BDST model (Fig. 7). The results of different bed height showed the validity of BDST model to study adsorption of TZ with the regression coefficient $\left(R^{2}\right)$ of 0.99 , (Table 4$)$. The value of adsorption capacity of the bed per unit of bed volume, $N_{\mathrm{o}}$ and the rate constant, $K_{\mathrm{a}}$ were computed from the slope and intercept of BDST plot assuming initial concentration, $C_{\mathrm{o}}$ and the linear velocity, as constant. The rate constant, $K_{\mathrm{a}}$ is a measure of the rate transfer of dye solution from the fluid phase to the solid phase. For TZ adsorption the values of $N_{\mathrm{o}}$ and $K_{\mathrm{a}}$ were $637.8 \mathrm{mg} / \mathrm{L}$ and $0.002 \mathrm{~L} / \mathrm{mg} \mathrm{h}$, The parameters obtained from BDST plot can be used to scaleup the process (Walker and Weatherley 1997).

A higher bed height indicates a larger amount of binding sites available. Similar observations also have been reported by several researchers (Unuabonah et al. 2010; Mulgundmath et al. 2012; Noreen et al. 2013). The longer exhaustion time $\left(t_{\mathrm{e}}\right.$, the time that the effluents reach the influent concentration) was observed by increasing the bed height from 8 to $12 \mathrm{~cm}$. The exhaustion time also increased from 425 to $790 \mathrm{~min}$ for TZ adsorption. After breakthrough time $\left(t_{\mathrm{b}}\right.$, the time that the effluents concentration start to be detected), the concentration of effluent of dyes TZ rapidly increases.

\section{Validity of kinetic models of fixed-bed column adsorption}

Dynamic adsorption is a complex process and its performance is controlled by many variables (Chen et al. 2012).

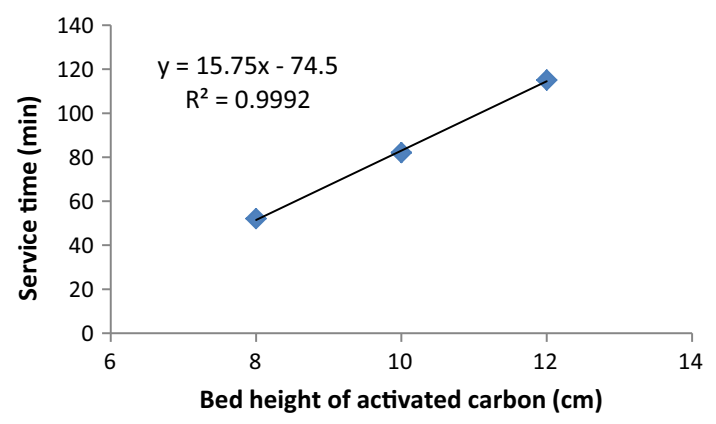

Fig. 7 BDST model plot for TZ adsorption onto activated carbon bed $\left(C_{\mathrm{o}}=15 \mathrm{mg} / \mathrm{L}, \mathrm{pH}=7\right.$, flow rate $=2.7 \mathrm{~mL} / \mathrm{min}$. $)$
In conducting packed-bed sorption experiments, normally the results are presented in terms of concentration time profile or breakthrough curve. The process of calculation is complicated and time consuming. Prediction of the adsorption rate and the maximum sorption bed capacity can be determined by applying certain mathematical models (Vaňková et al. 2010; Unuabonah et al. 2010).

Thomas model is widely used in predicting column performance modeling. Its derivation assume Langmuir isotherm for equilibrium, plug flow behavior in the bed and second-order reversible reaction kinetics. This model is suitable for studying fixed-bed adsorption processes where the internal and external diffusion limitations are negligible. The linearized form of Thomas model can be expressed as follows (Sidiras et al. 2011):

$\ln \left(\frac{C_{0}}{C_{\mathrm{t}}}-1\right)=\frac{k_{\mathrm{Th}} q_{\mathrm{e}} W}{Q}-k_{\mathrm{Th}} C_{0}(t)$

where $q_{\mathrm{e}}(\mathrm{mg} / \mathrm{g})$ is the equilibrium dye uptake per $\mathrm{g}$ of the adsorbent; $k_{\mathrm{Th}}(\mathrm{mL} / \mathrm{min} \mathrm{mg})$ is the Thomas rate constant; $C_{\mathrm{o}}(\mathrm{mg} / \mathrm{L})$ is the inlet concentration; $C_{\mathrm{t}}(\mathrm{mg} / \mathrm{L})$ is the outlet concentration at time $t ; Q(\mathrm{~mL} / \mathrm{min})$ the flow rate; $W(\mathrm{~g})$ the mass of adsorbent, and $(t)$ stands for flow time. The value of $C_{0} / C_{\mathrm{t}}$ is the ratio of inlet and outlet dye concentrations. A linear plot of $\ln \left[\left(C_{\mathrm{o}} / C_{\mathrm{t}}\right)-1\right]$ against time $(t)$ was employed to determine values of $k_{\mathrm{Th}}$ and $q_{\mathrm{e}}$ from the intercept and slope of the plot as shown in Figs. 8 and 9 for TZ adsorption.

The Thomas model gave a good fit of experimental data with high coefficient of determination, $R^{2}$ is greater than 0.92. The values of Thomas model show that the maximum adsorption capacities increases with increasing initial concentrations. However, the maximum adsorption capacities decrease with increases of flow rate. Table 6 shows the coefficient of determination values were varied from 0.92 to 0.98 with relative errors (RE) variation from 2.8 to

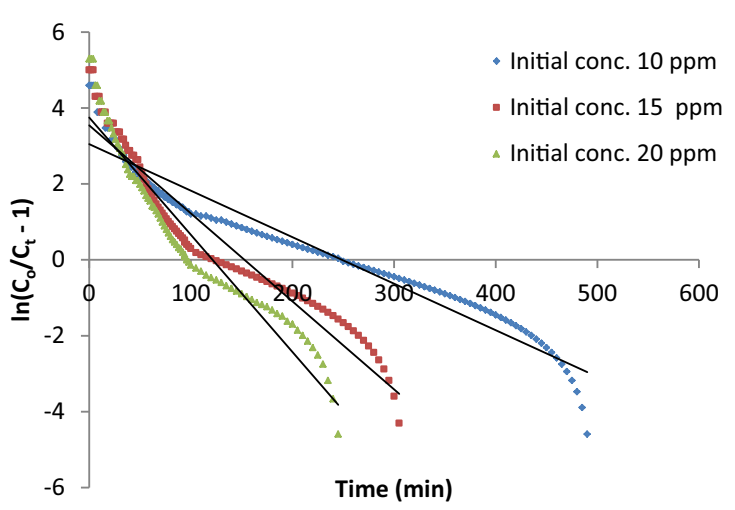

Fig. 8 Thomas model for adsorption of TZ on activated carbon at different initial concentration (flow rate of $2.7 \mathrm{~mL} / \mathrm{min}$, bed height of $10 \mathrm{~cm}$, temperature of $25^{\circ} \mathrm{C}$ ) 


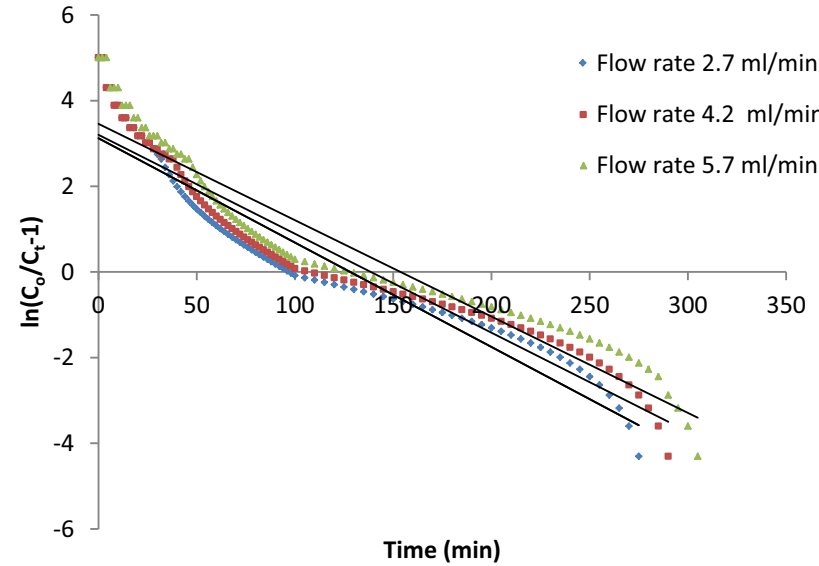

Fig. 9 Thomas model for adsorption of $\mathrm{TZ}$ on activated carbon at different flow rates (bed height of $10 \mathrm{~cm}$, Initial TZ concentration of $15 \mathrm{mg} / \mathrm{L}$, and temperature of $25^{\circ} \mathrm{C}$ )

8.9 which indicate a good agreement between the experimental data and the column data generated using the Thomas model. The rate constant, $K_{\mathrm{Th}}$ is observed to increase and decrease with the same pattern with $q_{\mathrm{e}}(\mathrm{mg} / \mathrm{g})$ (the calculated equilibrium dye uptake per gram of the adsorbent) (Futalan et al. 2011).

Bohart-Adams model which describes the initial part of a breakthrough profile is assumed to have rectangular shape isotherm. The model equation can be expressed as:

$\ln \left(\frac{C_{\mathrm{t}}}{C_{0}}\right)=k_{\mathrm{AB}} C_{0}(t)-\frac{k_{\mathrm{AB}} N_{0} Z}{L}$

where $C_{\mathrm{o}}$ and $C_{\mathrm{t}}$ are the initial and breakthrough concentrations $(\mathrm{mg} / \mathrm{L}), N_{\mathrm{o}}$ is fixed-bed sorption capacity per unit volume $(\mathrm{mg} / \mathrm{mL}), k_{\mathrm{AB}}(\mathrm{mL} / \mathrm{mg} \mathrm{min})$ is Bohart-Adams model's constant, $Z$ is the bed height, $L(\mathrm{~mL} / \mathrm{min})$ is the linear or superficial velocity and $t_{\mathrm{b}}$ is the breakthrough time. The model's parameters are obtained from the intercept and slope of a linear plot of $\ln \left[\left(C_{\mathrm{t}} / C_{0}\right)\right]$ against $t_{\mathrm{b}}$ as shown in Figs. 10 and 11 for TZ adsorption.

Linear regression results (Table 7) shown that adsorption capacity of the adsorbent $\left(N_{0}\right)$ and kinetic constant of the model $\left(k_{\mathrm{AB}}\right)$ increased with increasing initial dye concentration. However, because of more saturation of active carbon sites, adsorption capacity of the adsorbent $\left(N_{0}\right)$ decreased with increasing flow rate. In addition, kinetic constant of the model $\left(k_{\mathrm{AB}}\right)$ decrease with increasing flow rate. The lower $R^{2}$ values relative to the other model can be interpreted that the Adams-Bohart model is not as appropriate a predictor for the breakthrough curve (Rozada et al. 2003).

\section{Adsorption performance of prepared activated carbon}

The adsorption capacities of tartrazine over a variety of adsorbents are compared and reported in Table 8. The adsorption capacity of apricot stones based activated carbon prepared in this study was found to be larger than adsorption capacity accounted by several researcher from batch studies. Therefore, the activated carbon prepared in this work could be used as an effective adsorbent for removing azo-dye from aqueous solutions. However, the TZ adsorption capacity obtained from the column experiments was lower than the values obtained from the batch experiments for the same initial dye concentrations used. This might be due to the insufficient contact time between the dye ions in the solution and the adsorbent in the column. The difference between the batch and continuous capacity could also be attributed to the channeling of the flowing stream. Besides, the effective surface area of the activated carbons adsorbent packed in the column was lower than that in the batch process. Therefore, the performance of the activated carbon bed could be enhanced by applying a lower solution flow rate and/or using a higher bed height.

Table 6 Thomas model parameter of TZ adsorption on AC

\begin{tabular}{|c|c|c|c|c|c|c|c|}
\hline \multirow[t]{2}{*}{ Inlet conc. (mg/L) } & \multirow[t]{2}{*}{ Bed height, $\mathrm{H}$} & \multirow[t]{2}{*}{ Flow rate $(\mathrm{mL} / \mathrm{min})$} & \multicolumn{5}{|l|}{ Parameters } \\
\hline & & & $k_{\mathrm{Th}}(\mathrm{mL} / \mathrm{min} \mathrm{mg})$ & $q_{\mathrm{e}}(\mathrm{mg} / \mathrm{g})$ & $R^{2}$ & $q_{\mathrm{e}(\exp )}$ & $\mathrm{RE}$ \\
\hline \multicolumn{8}{|c|}{ Effect of initial concentration } \\
\hline 10 & 10 & 2.7 & 1.05 & 1.70 & 0.934 & 1.56 & 8.97 \\
\hline 15 & 10 & 2.7 & 1.12 & 1.86 & 0.973 & 1.78 & 4.49 \\
\hline 20 & 10 & 2.7 & 1.81 & 1.98 & 0.963 & 1.84 & 7.61 \\
\hline \multicolumn{8}{|l|}{ Effect of flow rate } \\
\hline 15 & 10 & 2.7 & 1.23 & 2.53 & 0.970 & 2.46 & 2.80 \\
\hline 15 & 10 & 4.2 & 1.11 & 2.35 & 0.948 & 2.28 & 3.07 \\
\hline 15 & 10 & 5.7 & 1.06 & 1.88 & 0.968 & 1.76 & 6.81 \\
\hline
\end{tabular}




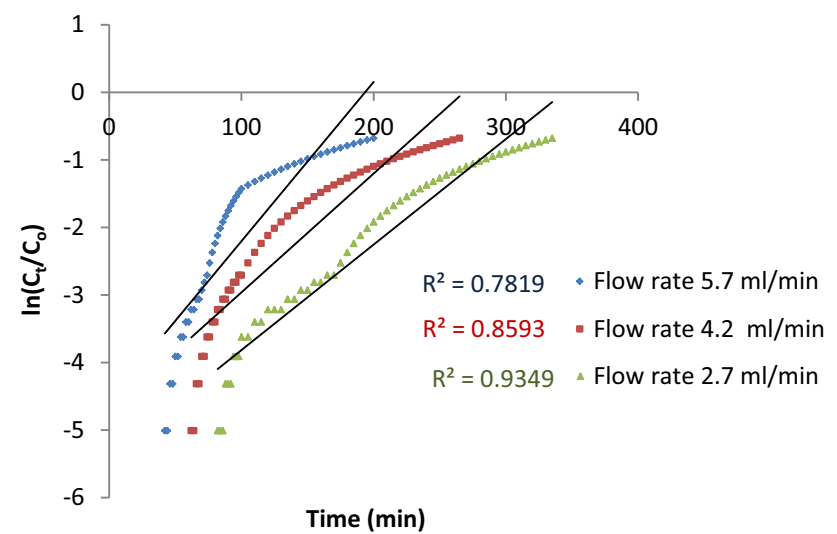

Fig. 10 Adam's-Bohart model for adsorption of TZ onto activated carbon at different flow rate (bed height of $10 \mathrm{~cm}$, Initial TZ concentration of $15 \mathrm{mg} / \mathrm{L}$, and temperature of $25^{\circ} \mathrm{C}$ )

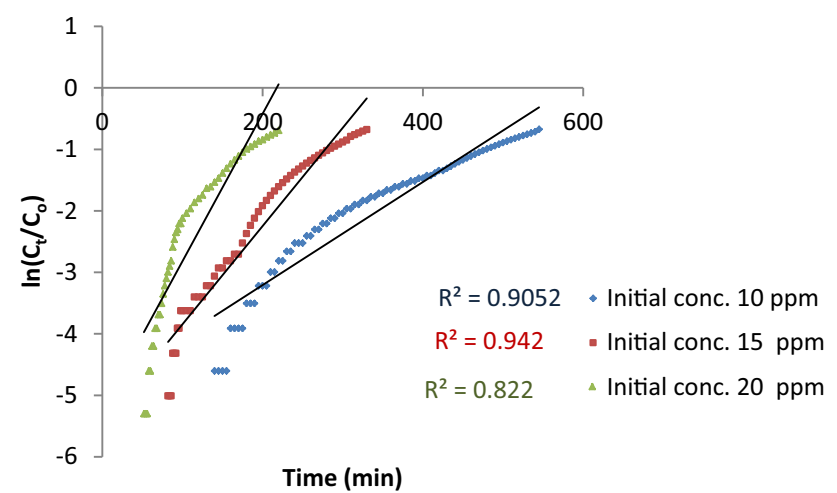

Fig. 11 Adam's-Bohart model for adsorption of $\mathrm{TZ}$ on activated carbon at different initial concentration (flow rate of $2.7 \mathrm{~mL} / \mathrm{min}$, bed height of $10 \mathrm{~cm}$, temperature of $25{ }^{\circ} \mathrm{C}$ )

Table 7 Adam-Bohart model parameter of TZ adsorption on AC

\begin{tabular}{|c|c|c|c|c|c|}
\hline \multirow{2}{*}{$\begin{array}{l}\text { Dye inlet } \\
\text { conc. }(\mathrm{mg} / \mathrm{L})\end{array}$} & \multirow{2}{*}{$\begin{array}{l}\text { Bed } \\
\text { height, } \\
\text { H }\end{array}$} & \multirow{2}{*}{$\begin{array}{l}\text { Flow rate } \\
(\mathrm{mL} / \mathrm{min})\end{array}$} & \multicolumn{3}{|l|}{ Parameters } \\
\hline & & & $\begin{array}{l}k_{\mathrm{AB}}(\mathrm{mL} / \\
\mathrm{mg} \cdot \mathrm{min})\end{array}$ & $\begin{array}{l}N_{0}(\mathrm{mg} / \\
\mathrm{mL})\end{array}$ & $R^{2}$ \\
\hline \multicolumn{6}{|c|}{ Effect of initial concentration } \\
\hline 10 & 10 & 2.7 & 0.50 & 1.57 & 0.90 \\
\hline 15 & 10 & 2.7 & 0.67 & 1.79 & 0.94 \\
\hline 20 & 10 & 2.7 & 0.81 & 2.19 & 0.82 \\
\hline \multicolumn{6}{|c|}{ Effect of flow rate } \\
\hline 15 & 10 & 2.7 & 0.62 & 2.83 & 0.93 \\
\hline 15 & 10 & 4.2 & 0.41 & 2.57 & 0.86 \\
\hline 15 & 10 & 5.7 & 0.30 & 1.78 & 0.78 \\
\hline
\end{tabular}

\section{Conclusions}

Activated carbon with surface areas $774 \mathrm{~m}^{2} / \mathrm{g}$ and $1.26 \mathrm{~cm}^{3} / \mathrm{g}$ pore volume can be produced from apricot stone by utilizing $\mathrm{H}_{3} \mathrm{PO}_{4}$ as an activating agent. The $\mathrm{N}_{2}$
Table 8 Comparison of the adsorption capacity of Apricot stonebased activated carbon with various adsorbents

\begin{tabular}{|c|c|c|}
\hline Adsorbent & $\begin{array}{l}\text { Maximum adsorption } \\
\text { capacity }(\mathrm{mg} / \mathrm{g})\end{array}$ & References \\
\hline $\begin{array}{l}\text { Jute processing } \\
\text { wastes }\end{array}$ & 22.47 & $\begin{array}{l}\text { Banerjee and } \\
\text { Dastidar (2005) }\end{array}$ \\
\hline Chitin & 30 & Dotto et al. (2012) \\
\hline $\begin{array}{l}\text { Polyaniline nano layer } \\
\text { composite }\end{array}$ & 2.47 & Ansari et al. (2011) \\
\hline Bottom ash & 12.6 & Mittal et al. (2006) \\
\hline Deoiled soya & 24.6 & Mittal et al. (2006) \\
\hline Amberlite IRA-900 & 49.88 & $\begin{array}{l}\text { Wawrzkiewicz and } \\
\text { Hubicki (2009) }\end{array}$ \\
\hline Amberlite IRA-910 & 49.96 & $\begin{array}{l}\text { Wawrzkiewicz and } \\
\text { Hubicki (2009) }\end{array}$ \\
\hline $\begin{array}{l}\text { Commercial activated } \\
\text { carbon }\end{array}$ & 4.48 & Jibril et al. (2013) \\
\hline Sawdust & 4.71 & \\
\hline $\begin{array}{l}\text { Apricot stone-based } \\
\text { activated carbon }\end{array}$ & 76 & This study \\
\hline
\end{tabular}

adsorption-desorption isotherm was a combination of types I and IV isotherms, which is corresponding to micro-mesoporous solid. Studies on continuous adsorption using a series of column experiments revealed that activated carbon prepared from apricot stones by $\mathrm{H}_{3} \mathrm{PO}_{4}$ activation has high ability to remove Tartrazine dye from aqueous solutions. The continuous adsorption system represented by the breakthrough curves was dependent on the initial dye concentration, bed height and the solution flow rate used. The results of different bed height showed the validity of BDST model to study adsorption of TZ with the regression coefficient $\left(R^{2}\right)$ of 0.99 . Comparison of Thomas and Adams-Bohart kinetic models with experimental data was performed and model parameters were determined by linear regression analysis for $\mathrm{TZ}$ adsorption under various operating conditions. The experimental data fit well with Thomas, but the Adams-Bohart model predicted poor performance of fixed-bed column.

Open Access This article is distributed under the terms of the Creative Commons Attribution 4.0 International License (http:// creativecommons.org/licenses/by/4.0/), which permits unrestricted use, distribution, and reproduction in any medium, provided you give appropriate credit to the original author(s) and the source, provide a link to the Creative Commons license, and indicate if changes were made.

\section{References}

Aguilar F, Charrondiere UR, Dusemund B, Galtier P, Gilbert J, Gott DM, Grilli S, Guertler R, Koenig J (2009) Scientific Opinion on 
the re-evaluation tartrazine (E 102). Eur Food Safety Auth $7(11): 1331$

Ahmad A, Hameed B (2010) Fixed-bed adsorption of reactive azo dye onto granular activated carbon prepared from waste. J Hazard Mater 175(1):298-303

Algidsawi AJK (2011) A study of ability of adsorption of some dyes on activated carbon from date' stones. Aust J Basic Appl Sci 5(11):1397-1403

Annadurai GJR, Lee DJ (2002) Adsorption of heavy metals from water using banana and orange peels. Water Sci Technol 47(1):185-190

Annadurai GJRS, Lee DJ, Juang Ruey-Shin, Lee Duu-Jong (2002) Use of cellulose-based wastes for adsorption of dyes from aqueous solutions. J Hazard Mater B92:263-274

Ansari R, Banimahd Keivani M, Fallah Delavar A (2011) Application of polyaniline nanolayer composite for removal of tartrazine dye from aqueous solutions. J Polym Res 18(6):1931-1939. doi:10. 1007/s10965-011-9600-Z

Aygun A, Karakas S, Duman I (2003) Production of granular activated carbon from fruit stones and nutshells and evaluation of their physical, chemical and adsorption properties. Micropor Mesopor Mater 66:189-195

Banerjee S, Dastidar M (2005) Use of jute processing wastes for treatment of wastewater contaminated with dye and other organics. Bioresour Technol 96(17):1919-1928

Baraka A (2012) Adsorptive removal of tartrazine and methylene blue from wastewater using melamine-formaldehydetartaric acid resin (and a discussion about pseudo second order model). Desalination Water Treat 44:128-141

Casas N, Schell J, Pini R, Mazzotti M (2012) Fixed bed adsorption of $\mathrm{CO}_{2} / \mathrm{H}_{2}$ mixtures on activated carbon: experiments and modeling. Adsorption 18(2):143-161

Chen S, Yue Q, Gao B, Li Q, Xu X, Fu K (2012) Adsorption of hexavalent chromium from aqueous solution by modified corn stalk: a fixed-bed column study. Bioresour Technol 113:114-120

Crhribi A, Chlendi M (2011) Modeling of fixed bed adsorption: application to the adsorption of an organic dye. Asian $\mathrm{J}$ Textile $1: 161-171$

Deng H, Yang L, Tao G, Dai J (2009) Preparation and characterization of activated carbon from cotton stalk by microwave assisted chemical activation-application in methylene blue adsorption from aqueous solution. $\mathrm{J}$ Hazard Mater 166(2-3):1514-1521. doi:10.1016/j.jhazmat.2008.12.080

Dotto GL, Vieira MLG, Pinto LAA (2012) Kinetics and mechanism of tartrazine adsorption onto chitin and chitosan. Ind Eng Chem Res 51(19):6862-6868. doi:10.1021/ie2030757

Dutta M, Basu J (2014) Fixed-bed column study for the adsorptive removal of acid fuchsin using carbon-alumina composite pellet. Int J Environ Sci Technol 11(1):87-96

Elsayed M, Zalat O (2015) Factor affecting microwave assisted preparation of activated carbon from local raw materials. Int Lett Chem Phys Astron 8(1):15

Futalan CM, Kan C-C, Dalida ML, Pascua C, Wan M-W (2011) Fixed-bed column studies on the removal of copper using chitosan immobilized on bentonite. Carbohydr Polym 83(2):697-704

Gautam RK, Mudhoo A, Chattopadhyaya MC (2013) Kinetic, equilibrium, thermodynamic studies and spectroscopic analysis of Alizarin Red S removal by mustard husk. J Environ Chem Eng 1(4):1283-1291

Gautam RK, Gautam PK, Chattopadhyaya M, Pandey J (2014a) Adsorption of alizarin red s onto biosorbent of lantana camara: kinetic, equilibrium modeling and thermodynamic studies. Proc Natl Acad Sci India Sect A Phys Sci 84(4):495-504

Gautam RK, Mudhoo A, Lofrano G, Chattopadhyaya MC (2014b) Biomass-derived biosorbents for metal ions sequestration: adsorbent modification and activation methods and adsorbent regeneration. J Environ Chem Eng 2(1):239-259

Gautam RK, Gautam PK, Banerjee S, Rawat V, Soni S, Sharma SK, Chattopadhyaya MC (2015a) Removal of tartrazine by activated carbon biosorbents of Lantana camara: kinetics, equilibrium modeling and spectroscopic analysis. J Environ Chem Eng 3(1):79-88

Gautam RK, Rawat V, Banerjee S, Sanroman MA, Soni S, Singh SK, Chattopadhyaya MC (2015b) Synthesis of bimetallic Fe-Zn nanoparticles and its application towards adsorptive removal of carcinogenic dye malachite green and Congo red in water. J Mol Liq 212:227-236

Grégorio Crini P-MB (2010) Sorption processes and pollution: Conventional and non-conventional sorbents for pollutant removal from wastemasters. Presses Univ, Franche-Comté

Gupta V, Gupta B, Rastogi A, Agarwal S, Nayak A (2011) A comparative investigation on adsorption performances of mesoporous activated carbon prepared from waste rubber tire and activated carbon for a hazardous azo dye-acid blue 113 . J Hazard Mater 186(1):891-901

Gurses AKS, Dogar C, Bayrak R, Acikyildiz M, Yalcin M (2004) Determination of adsorptive properties of clay/water system: methylene blue sorption. J Colloid Interface Sci 269(2):310-314

Jibril M, Noraini J, Poh LS, Evuti AM (2013) Removal of colour from waste water using coconut shell activated carbon (CSAC) and commercial activated carbon (CAC). Jurnal Teknologi 60(1):15-19

Kadirvelu K, Kavipriya M, Karthika C, Radhika M, Vennilamani N, Pattabhi S (2003) Utilization of various agricultural wastes for activated carbon preparation and application for the aqueous solutions. Bio Resour Technol 87:129-132

Karunarathne H, Amarasinghe B (2013) Fixed bed adsorption column studies for the removal of aqueous phenol from activated carbon prepared from sugarcane bagass. Energy Proc 34:83-90

Khoo E-C, Ong S-T, Ha S-T (2012) Removal of basic dyes from aqueous environment in single and binary systems by sugarcane bagasse in a fixed-bed column. Desalination Water Treat $37(1-3): 215-222$

Klán P, Vavrik M (2006) Non-catalytic remediation of aqueous solutions by microwave-assisted photolysis in the presence of $\mathrm{H}_{2} \mathrm{O}_{2}$. J Photochem Photobiol A 177(1):24-33. doi:10.1016/j. jphotochem.2005.05.008

Mittal A, Mittal J, Kurup L (2006) Adsorption isotherms, kinetics and column operations for the removal of hazardous dye, tartrazine from aqueous solutions using waste materials-bottom ash and de-oiled soya, as adsorbents. J Hazard Mater 136(3):567-578. doi:10.1016/j.jhazmat.2005.12.037

Mulgundmath V, Jones R, Tezel F, Thibault J (2012) Fixed bed adsorption for the removal of carbon dioxide from nitrogen: breakthrough behaviour and modelling for heat and mass transfer. Sep Purif Technol 85:17-27

Namasivayam CRR, Suba S (2001) Uptake of dyes by a promising locally available agricultural solid waste: coir pith. J Waste Manag 2:381-387

Noreen S, Bhatti HN, Nausheen S, Sadaf S, Ashfaq M (2013) Batch and fixed bed adsorption study for the removal of drimarine black CL-B dye from aqueous solution using a lignocellulosic waste: a cost affective adsorbent. Ind Crops Prod 50:568-579

Robinson T, McMullan G, Marchant R, Nigam P (2001) Remediation of dyes in textiles effluent: a critical review on current treatment technologies with a proposed alternative. Bioresour Technol 77:247-255

Robinson T, Chandran B, Nigam P (2002) Studies on desorption of individual textile dyes and a synthetic dye effluent from dye adsorbed agricultural residues using solvents. Bioresour Technol 58:217-227

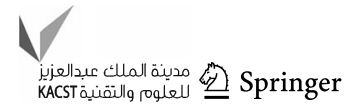


Rozada F, Calvo L, Garcıa A, Martın-Villacorta J, Otero M (2003) Dye adsorption by sewage sludge-based activated carbons in batch and fixed-bed systems. Bioresour Technol 87(3):221-230

Santhy K, Selvapathy P (2006) Removal of reactive dyes from wastewater by adsorption on coir pith activated carbon. Bioresour Technol 97(11):1329-1336

Sidiras D, Batzias F, Schroeder E, Ranjan R, Tsapatsis M (2011) Dye adsorption on autohydrolyzed pine sawdust in batch and fixedbed systems. Chem Eng J 171(3):883-896

Unuabonah EI, Olu-Owolabi BI, Fasuyi EI, Adebowale KO (2010) Modeling of fixed-bed column studies for the adsorption of cadmium onto novel polymer-clay composite adsorbent. J Hazard Mater 179(1):415-423
Vaňková K, Ačai P, Polakovič M (2010) Modelling of fixed-bed adsorption of mono-, di-, and fructooligosaccharides on a cationexchange resin. Biochem Eng J 49(1):84-88

Walker G, Weatherley L (1997) Adsorption of acid dyes on to granular activated carbon in fixed beds. Water Res 31(8):2093-2101

Wawrzkiewicz M, Hubicki Z (2009) Removal of tartrazine from aqueous solutions by strongly basic polystyrene anion exchange resins. J Hazard Mater 164(2-3):502-509. doi:10.1016/j. jhazmat.2008.08.021

Yavuz Ö, Aydin AH (2006) Removal of direct dyes from aqueous solution using various adsorbents. Pol $\mathrm{J}$ Environ Stud 15(1):155-161 